\title{
Biomineralization in chitosan/Bioglass $®$ composite membranes under different dynamic mechanical conditions
}

\author{
Sofia G. Caridade a,b Esther G. Merino ${ }^{\mathrm{a}, \mathrm{b}}$, Natália M. Alves ${ }^{\mathrm{a}, \mathrm{b}}$, João F. Mano ${ }^{\mathrm{a}, \mathrm{b}, *}$

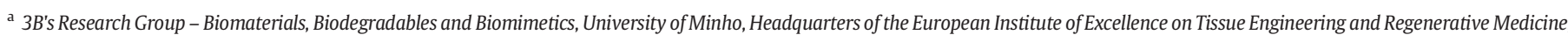 \\ AvePark, 4806-909, Taipas, Guimarães, Portugal \\ b ICVS/3B's - PT Government Associate Laboratory, Braga/Guimarães, Portugal
}

\section{A R T I C L E I N F O}

\section{Article history:}

Received 4 April 2013

Received in revised form 16 June 2013

Accepted 27 June 2013

Available online 4 July 2013

\section{Keywords:}

Tissue engineering

Biomimetics

Dynamic mechanical analysis

Non-destructive tests

Bioactive composites

Mineralization

\begin{abstract}
A B S T R A C T
Fundamental aspects of biomineralization may be important in order to understand and improve calcification onto the surface of biomaterials. The biomineralization process is mainly followed in vitro by assessing the evolution of the apatite layer that is formed upon immersion of the material in Simulated Body Fluid (SBF). In this work we propose an innovative methodology to monitor apatite deposition by looking at the evolution of the mechanical/viscoelastic properties of the sample while immersed in SBF, using non-conventional dynamic mechanical analysis (DMA) performed under distinct displacement amplitudes (d). The biomimetic biomineralization process in composite membranes of chitosan (CTS) with Bioglass ${ }^{\circledR}$ (BG) was followed by measuring the change of the storage modulus, $E^{\prime}$, and the loss factor, tan $\delta$, at $37^{\circ} \mathrm{C}$ and in SBF, both online $(\mathrm{d}=10 \mu \mathrm{m}$ and $\mathrm{d}=30 \mu \mathrm{m})$ and offline $(\mathrm{d}=0 \mu \mathrm{m})$. The online experiments revealed that the $E^{\prime}$ decreased continuously up in the first hours of immersion in SBF that should be related to the dissolution of BG particles. After that, an increase of the stiffness was verified due to the apatite deposition. SEM/EDS observations upon $24 \mathrm{~h}$ of immersion in SBF showed higher development of apatite deposition with increasing displacement amplitude.
\end{abstract}

(C) 2013 Elsevier B.V. All rights reserved.

\section{Introduction}

In the last years, many strategies have been employed in order to confer bioactivity to biomaterials aimed to be used in the orthopedic field $[1,2]$. Much research has been done in order to understand the mechanism of mineralization of such materials. A common characteristic of such bioactive materials is a time-dependent, kinetic modification of the surface that occurs upon implantation. Such surface forms a bone-like apatite layer that provides the bonding interface with bone tissue. The morphological, structural and chemical characterization of the formed calcified layer is typically performed at pre-determined time points after immersion in aqueous physiological-like fluids. Such aqueous solutions simulate different properties of human plasma, such as $\mathrm{pH}$ and ionic composition. Usually, when bioactive materials are in contact with any of these solutions, three phenomena occur: release of ions, $\mathrm{pH}$ modifications and growth of an apatite layer on the glass surface [3]. To explain the evolution of the reaction between the bioactive materials and its surrounding medium different protocols

\footnotetext{
* Corresponding author at: 3B’s Research Group - Biomaterials, Biodegradables and Biomimetics, University of Minho, Headquarters of the European Institute of Excellence on Tissue Engineering and Regenerative Medicine, Ave. Park, 4806-909, Taipas, Guimarães, Portugal.

E-mail addresses: sofia.caridade@dep.uminho.pt (S.G. Caridade), egarciamerino@yahoo.es (E.G. Merino), nalves@dep.uminho.pt (N.M. Alves), jmano@dep.uminho.pt (J.F. Mano).
}

have been tested. To carry out in-vitro study, different aqueous biological fluids such as, Tris buffer [4], simulated body fluid (SBF) [5,6], newborn bovine serum [7] and some cell culture media such as Dulbecco's modified Eagle's medium $[8,9]$ have been used. Moreover, several protocols have been tested in which the assay can be performed in a static medium [10-12], renewed at pre-determined time [13], renewed with continuous stirring or in a dynamic medium where the solution is constantly exchanged with a peristaltic pump or under circulating flow perfusion conditions [14-17].

The description of the biomineralization process in real time may provide information about the calcification kinetics and mechanism and could also describe the evolution of useful properties of the biomaterial. However until now, just few studies have followed the biomineralization process in situ [18-22]. Leonor et al. reported the change in the surface topography by monitoring in situ using atomic force microscopy while apatite was deposited onto a biodegradable bioactive substrate [18]. Also, real-time, in situ quartz crystal microbalance measurements were conducted to better understand the crystallization of calcium phosphates onto substrates [19]. Other techniques could be also used to follow the biomineralization process in situ and extract valuable information. DMA demonstrated be an adequate technique for characterizing the mechanical features of biomaterials [23], as one can use test conditions that closely simulate the physiological environment. Previous works reported that biomaterials tested in buffered solutions at $37{ }^{\circ} \mathrm{C}$ show a completely different viscoelastic behavior to the observed in the typical 
dry conditions [24,25]. Such kind of studies strengthens the need of performing mechanical tests in biomaterials with water uptake capability under physiological-like conditions. On a previous work [21], the biomineralization process was, for the first time, followed in real time using DMA where online experiments were used to monitor the change in the viscoelastic properties of CTS/BG composite membranes immersed in SBF during the first $24 \mathrm{~h}$. The motivation was that, if the biomaterial possesses osteoconductive properties it should promote the deposition of apatite and its mechanical properties could be changed and followed in real time. The online experiments revealed that the $E^{\prime}$ decreased continuously up in the first hours of immersion in SBF, that being related to the dissolution of BG particles. After that, an increase of the stiffness was verified due to the apatite deposition. This work demonstrated the possibility of using real-time mechanical characterization to monitor the process of biomineralization and provided information about the calcification kinetics and mechanism. However, the effect of the displacement amplitude was not analysed. We hypothesise that such parameter will influence the ion dissolution profile and thus, the evolution of the apatite deposition and the change of the mechanical properties of the composite membrane.

In this work, we propose to monitor the precipitation of the apatite layer under different mechanical dynamic conditions over composites membranes upon immersion in SBF using in situ DMA. If one can recreate the physiological environments in the bioactivity tests, these DMA experiments could help in predicting the evolution of the mechanical/viscoelastic performance of bioactive implants upon implantation, including under distinct loading conditions. To demonstrate the applicability of the proposed methodology, we tested flexible bioactive membranes obtained by the combination of CTS and BG particles. The biomineralization process was followed by measuring the change of the storage modulus, $E^{\prime}$, and the loss factor, $\tan \delta$, at $37{ }^{\circ} \mathrm{C}$ and in SBF, both online and offline.

In literature, other studies have reported such kind of chitosan-based bioactive systems [26-29]. For example, Leonor et al., [30] demonstrated the growth of a bonelike apatite on chitosan microparticles after a calcium silicate treatment. They showed that such system can be used as an injectable bone substitute that can also act as a drug delivery system. Lee et al., [26] prepared a membrane of hybrid chitosan-silica xerogel that presented superior mechanical properties and excellent in-vitro bioactivity than pure chitosan membranes. They reported that, such hybrid membranes can be used for guided bone regeneration.

As in in-vivo conditions tissues are subjected to mechanical stimuli with distinct intensities, the motivation of this work was observed which effects could occurred in the mineralization process by doing the samples oscillating at different displacements.

\section{Materials and methods}

\subsection{Materials}

Chitosan (medium molecular weight) was purchased from Sigma-Aldrich, Germany, and was purified prior to use. The degree of $N$-deacetylation (DD) was found to be $78.7 \%$ by the first derivative ultraviolet spectrophotometry, using both glucosamine (GluN) and $\mathrm{N}$-acetylglucosamine (GluNAc) standards for calibration [31]. The molecular weight $\left(\mathrm{M}_{\mathrm{v}}\right)$ was determined by viscometry in $\mathrm{CH}_{3-}$ $\mathrm{COOH} 0.5 \mathrm{M} / \mathrm{NaCH}_{3} \mathrm{COO} 0.2 \mathrm{M}$, which was found to be $770 \mathrm{kDa}$ according to the Mark-Houwing theory $\left(\mathrm{k}=3.5 \times 10^{-4}\right.$; $\mathrm{a}=0.76$ ) [32]. The Bioglass ${ }^{\circledR}$ (45S5) with particle size of $5 \mu \mathrm{m}$ was supplied by US Biomaterials Corp. (Florida, USA). The SBF [33] was prepared by dissolving $\mathrm{NaCl}$ (ACS reagent, $\geq 99.0 \%$ purity), $\mathrm{NaHCO}_{3}$ (ACS reagent, $\geq 99.7 \%$ purity), $\mathrm{KCl}$ (ACS reagent, $\geq 99.0 \%$ purity), $\mathrm{K}_{2} \mathrm{HPO}_{4} .3 \mathrm{H}_{2} \mathrm{O}$ (ReagentPlus ${ }^{\circledR}, \geq 99.0 \%$ purity), $\mathrm{MgCl}_{2} \cdot 6 \mathrm{H}_{2} \mathrm{O}$ (ACS reagent, $\geq 99.0 \%$ purity), $\mathrm{CaCl}_{2}$ (ACS reagent, $\geq 96.0 \%$ purity) and $\mathrm{Na}_{2} \mathrm{SO}_{4}$ (ACS reagent, $\geq 99.0 \%$ purity) in distilled water and buffered with Tris buffer (ACS reagent, $\geq 99.8 \%$ purity) and $\mathrm{HCl}$ (ACS reagent) to reach a $\mathrm{pH}$ value of
7.4. All Chemicals for simulated body fluid (SBF) preparation were obtained from Sigma-Aldrich, Germany. All other reagents and solvents used were of reagent grade and were used without further purification.

\subsection{Membranes preparation}

Composite membranes, CTS/BG, were prepared by solvent casting. First, chitosan was dissolved at $1 \mathrm{wt}$ \% in $1 \mathrm{wt}$ \% aqueous acetic acid and filtered to remove impurities. After, $30 \mathrm{wt} \%$ of BG was added to the polymer solution. This mixture was stirred during $2 \mathrm{~h}$ and then sonicated for $15 \mathrm{~min}$. The solutions were cast in Petri dishes and left to dry at room temperature. After drying, CTS/BG composite membranes were peeled off and neutralized in a $0.1 \mathrm{M} \mathrm{NaOH}$ solution for about $10 \mathrm{~min}$, washed thoroughly with distilled water and dried again.

\subsection{Bioactivity tests}

For the in vitro bioactivity tests an acellular simulated body fluid (SBF) (1.0x) was prepared, with ions concentration nearly equal to human blood plasma. The SBF composition and preparation was previously described by Kokubo and co-workers [33]. Sample membranes of $20 \times 15 \mathrm{~mm}^{2}$ were cut from the original processed films for the bioactivity tests. Three replicates for each sample were immersed in SBF for 1 day at $37^{\circ} \mathrm{C}$. After being removed from SBF, the sample membranes were gently rinsed with distilled water and dried at room temperature.

\subsection{Physical characterization of materials}

\subsubsection{Scanning electron microscopy (SEM)}

The morphological analysis of the samples (after and before of bioactivity test) was performed using Scanning Electron Microscope (SEM, Leica Cambridge S 360) at an accelerated voltage of $15 \mathrm{kV}$. Before being observed by SEM, the membranes were gold coated using a Hitachi coater at $6 \mathrm{~mA}$. After DMA experiments, the composite membranes were gently rinsed with distilled water and dried at room temperature. Such drying step made cracks in the apatite layers formed being used to estimate their thicknesses by SEM. The surfaces of all samples were always put in an orientation of $45^{\circ}$ in the SEM apparatus in order to have always the same inclination for the measurements. At least three measures were taken for each condition.

\subsubsection{Energy dispersive spectroscopy (EDS)}

Samples of the polymeric matrixes prepared were observed by a Leica Cambridge S360 Scanning Electron Microscope. The matrixes were fixed by mutual conductive adhesive tape on aluminium stubs and covered with carbon palladium using a sputter coater. After immersion in SBF the samples were again analysed in order to check the appearance of a calcium-phosphate layer on the surface of the matrixes.

\subsection{Dynamic Mechanical Analysis (DMA)}

All viscoelastic measurements were performed using a TRITEC2000B DMA from Triton Technology (UK), equipped with the tensile mode. The measurements were carried out at $37^{\circ} \mathrm{C}$. The membrane samples were cut at about $4 \mathrm{~mm}$ width (measured accurately for each sample). CTS/BG were always analyzed immersed in a liquid bath placed in a Teflon ${ }^{\circledR}$ reservoir. Two different experiments were performed: one was in real-time and the other one was offline. In the online experiments, two different displacement amplitudes (d) were used during the DMA measurements: 10 and $30 \mu \mathrm{m}$. In the online measurements the membranes were immersed in SBF up to equilibration and then the measurements were done always keeping the membrane inside the apparatus. The motivation was to observe in real time the changes in the viscoelastic properties of the materials in a solution that induces mineralization under different cyclic amplitude displacements. The offline experiments 
A

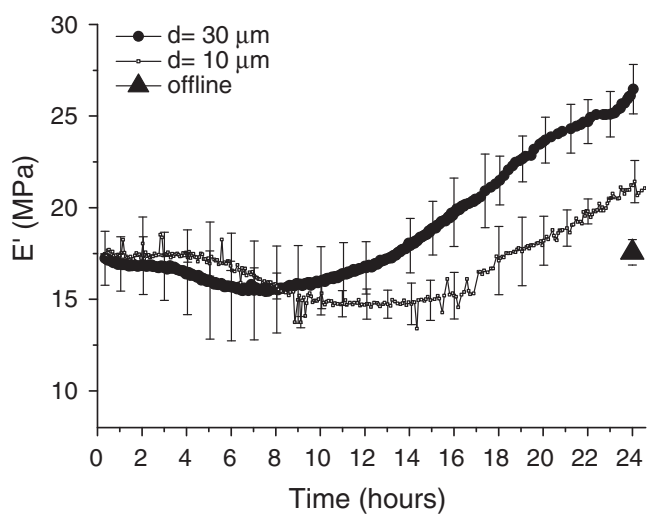

B

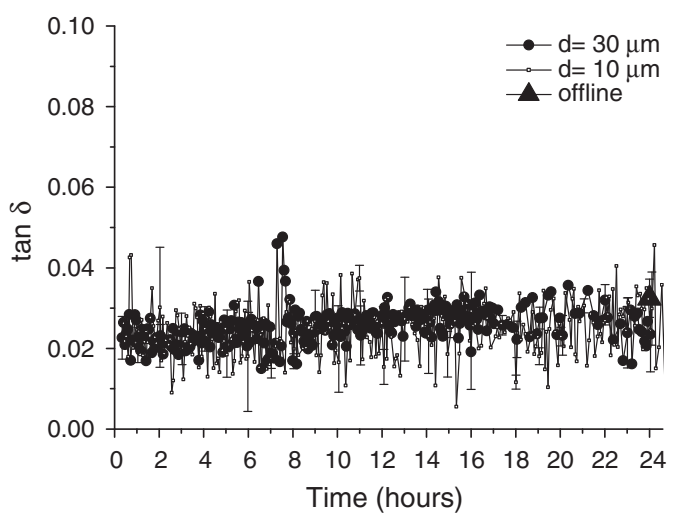

Fig. 1. A: storage modulus and B: loss factor of DMA measurements at $1 \mathrm{~Hz}$ on the CTS and CTS/BG membranes while immersed in SBF for the first $24 \mathrm{~h}$.

were performed by measuring the sample in the DMA after being immersed in SBF for a period of $24 \mathrm{~h}$ ("static" experiment). The procedure below was used for both online and offline experiments. The geometry of the samples was then measured and the samples were clamped in the DMA apparatus (the distance between the clamps was $10 \mathrm{~mm}$ ) and immersed in the liquid bath. After equilibration at $37^{\circ} \mathrm{C}$, the DMA spectra were obtained during a frequency scan between 0.1 and $10 \mathrm{~Hz}$. A static pre-load of $1 \mathrm{~N}$ was applied during the tests to keep the sample tight. Three specimens were tested for each condition.

\section{Results and discussion}

The description of the biomineralization process in real time may provide information about the calcification kinetics and mechanism and could describe the evolution of the properties of the biomaterial. Our group reported, for the first time, the monitoring of the biomineralization process in real time using DMA [21]. In another study [22] the biomineralization process was also followed in real time by using DMA where a faster mineralization kinetic was observed for CTS/BG composite membranes containing nanosized bioactive glass particles, as compared with the composites with micro sized particles. It is known that the biomineralization process is dependent of several factors and that the living tissues are subjected to mechanical loads with distinct intensities. We hypothesise that such behavior could be recreated by analyzing the biomineralization while the sample is loaded with different displacement amplitudes. For that, DMA experiments were performed, both online ("dynamic") and offline ("static"), where the viscoelastic properties were followed in wet conditions as a function of immersion time in SBF. The offline experiments were carried out for a period of $24 \mathrm{~h}$ : after soaking the membranes during $24 \mathrm{~h}$ in SBF, under static conditions (i.e. no dynamic load was imposed during soaking in SBF), the samples were placed in the DMA apparatus and tested after equilibration at $37{ }^{\circ} \mathrm{C}$ immersed in SBF. Fig. 1 shows the change in the viscoelastic parameters of the composite membranes immersed in SBF for a period of $24 \mathrm{~h}$. Changes were detected on the CTS/BG membranes during the mineralization process just by changing the displacement conditions. The online experiments revealed that when immersed in SBF, the storage modulus, $E^{\prime}$, decreases continuously up to ca. $7 \mathrm{~h}$ (in the case of CTS/BG subjected to a displacement of $\mathrm{d}=30 \mu \mathrm{m}$ ) and up to ca. $12 \mathrm{~h}$ (for CTS/BG subjected to a displacement of $\mathrm{d}=10 \mu \mathrm{m}$ ) of immersion in SBF indicating that the BG particles are being dissolved from the membranes. After such periods of time $E^{\prime}$ stabilizes and starts to increase (ca. $12 \mathrm{~h}$ for the CTS/BG subjected to $\mathrm{d}=30 \mu \mathrm{m}$ and ca. $17 \mathrm{~h}$ for CTS/BG subjected to $\mathrm{d}=10 \mu \mathrm{m})$, with increasing immersion time in SBF

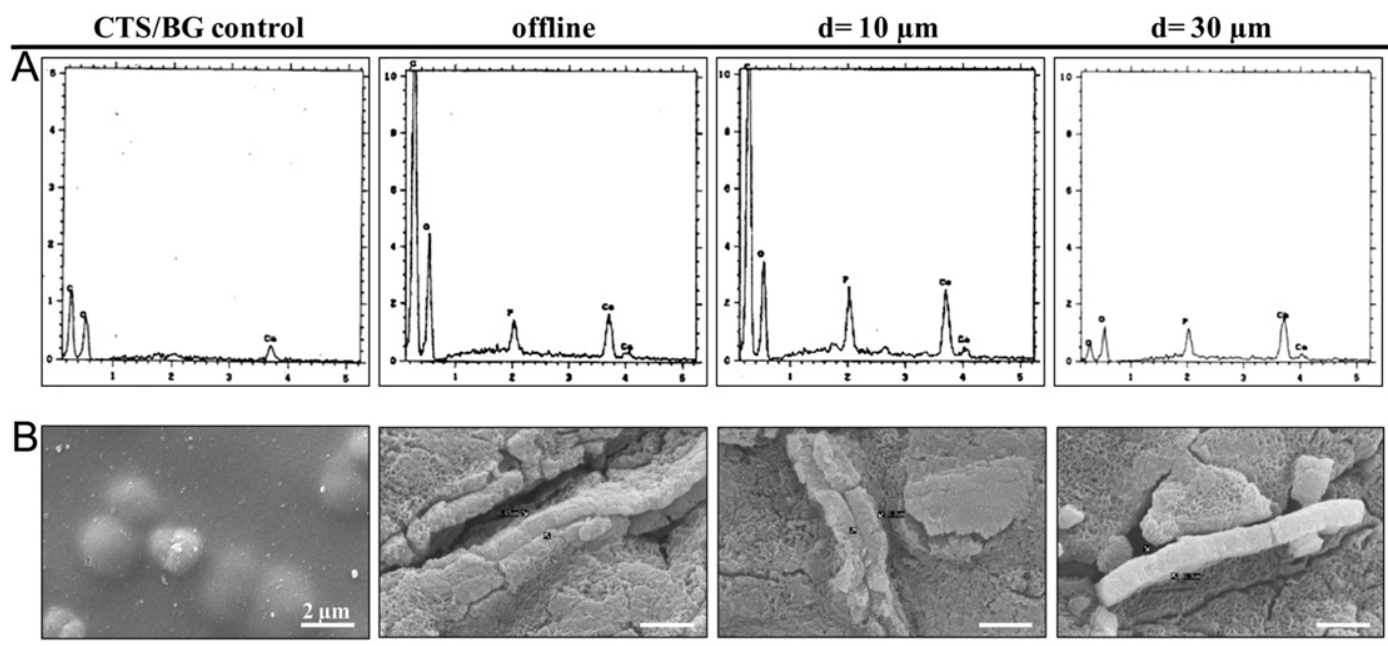

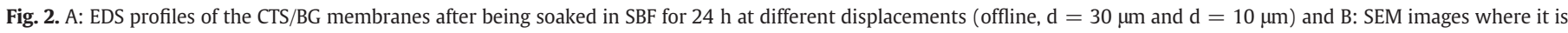


CTS/BG control corresponds to the composite membrane before soaking in SBF. The scale bar is $2 \mu \mathrm{m}$. 
indicating that an apatite layer is being formed (Fig. 1A). Although all the conditions tested indicate the formation of an apatite layer, the CTS/BG that are subjected to $\mathrm{d}=30 \mu \mathrm{m}$ present a faster kinetic of hydroxyapatite formation. An explanation to this behavior is that, the release of ions by diffusion is favored by employing a higher displacement to the CTS/BG. This ions exchange by the BG particles and the SBF lead to the formation of a hydrated silica gel layer which is abundant in silanol groups $(\mathrm{Si}-\mathrm{OH})$ that provides favorable sites for calcium phosphate nucleation. Once the apatite nuclei are formed, they grow spontaneously into a dense and uniform layer of bone-like apatite. Similar results were obtained in another work, where the kinetic of apatite formation was higher in composite membranes made of CTS and nano BG [22]. Fig. 1B shows that, the loss factor $(\tan \delta)$ values of the composite membranes do not exhibit significant variation with the previous immersion period in SBF. This means that the in-vitro mineralization process of the biomaterial does not influence significantly its damping properties. EDS and SEM observations were performed on the samples, to investigate the apatite deposition occurred upon $24 \mathrm{~h}$ immersion time in SBF on the CTS/BG composite membranes (Fig. 2). Fig. 2A shows the EDS spectra of the CTS/BG that were subjected to the various DMA conditions aforementioned. After only $24 \mathrm{~h}$ in SBF, all the conditions studied present an increase on the intensity of both calcium (Ca) and phosphorous $(\mathrm{P})$ peaks relatively to the CTS/BG control indicating the development of an apatite layer. In particular, one could detect a relative increase of the $P$ and $C a$ peaks with respect to the $C$ and $O$ peaks for the sequence: static $(\mathrm{d}=0 \mu \mathrm{m}), \mathrm{d}=10 \mu \mathrm{m}$ and $\mathrm{d}=30 \mu \mathrm{m}$.

Fig. 2B shows the surfaces of the composite membranes after DMA experiments where the samples were gently rinsed with distilled water and dried at room temperature for SEM observation. The cracks in the apatite layers can be used to estimate the thickness of the apatite component (Fig. 2B). A thickness of $0.68 \pm 0.04 \mu \mathrm{m}, 0.85 \pm 0.07 \mu \mathrm{m}$ and $0.97 \pm 0.05 \mu \mathrm{m}$ was measured for the membranes that were tested in static conditions (offline experiment) and, with the membranes that were subjected to $\mathrm{d}=10 \mu \mathrm{m}$ and $\mathrm{d}=30 \mu \mathrm{m}$, respectively. Such results reinforced the hypothesis that the mineralization process can be regulated just by changing the stimulations that are applied to a material. Moreover, as observed in DMA experiments, it seems that the kinetic of apatite formation is faster on the CTS/BG membranes that were subjected to a displacement of $30 \mu \mathrm{m}$. Taken all together, such results indicated that the apatite layer formation and stiffness can be controlled depending on the stimulus that is employed to a material during biomineralization.

\section{Conclusions}

CTS/BG composites membranes were prepared at room temperature using a solvent casting process. It was possible to follow the biomineralization process in-vitro using in-situ dynamic mechanical analysis. As the living tissues are subjected to different mechanical stimulus in the body, online DMA tests were performed at different cyclic displacement amplitudes: 10 and $30 \mu \mathrm{m}$. Online DMA tests permitted to follow the calcification process in SBF and a faster kinetic of apatite formation was verified on the CTS/BG membranes that were subjected to a displacement of $30 \mu \mathrm{m}$.

\section{Acknowledgements}

This work was financially supported by Foundation for Science and Technology (FCT) by the projects PTDC/QUI/69263/2006, PTDC/ CTM-BPC/112774/2009 and, through the scholarship SFRH/BD/64601/ 2009 granted to Sofia G. Caridade.

\section{References}

[1] N.M. Alves, I.B. Leonor, H.S. Azevedo, R.L. Reis, J.F. Mano, J. Mater. Chem. 20 (2010) 2911-2921.

[2] K. Rezwan, Q.Z. Chen, J.J. Blaker, A.R. Boccaccini, Biomaterials 27 (2006) 3413-3431.

[3] D. Arcos, D.C. Greenspan, M. Vallet-Regi, J. Biomed. Mater. Res. Part A 65A (2003) 344-351.

[4] D. Rohanova, A.R. Boccaccini, D.M. Yunos, D. Horkavcova, I. Brezovska, A. Helebrant, Acta Biomater. 7 (2011) 2623-2630.

[5] T. Kokubo, H. Kushitani, S. Sakka, T. Kitsugi, T. Yamamuro, J. Biomed. Mater. Res. 24 (1990) 721-734.

[6] M. Vallet-Regi, J. Perez-Pariente, I. Izquierdo-Barba, A.J. Salinas, Chem. Mater. 12 (2000) 3770-3775.

[7] S. Radin, P. Ducheyne, B. Rothman, A. Conti, J. Biomed. Mater. Res. 37 (1997) 363-375.

[8] V. Aina, G. Malavasi, A.F. Pla, L. Munaron, C. Morterra, Acta Biomater. 5 (2009) 1211-1222.

[9] G. Lutisanova, M.T. Palou, J. Kozankova, Ceram.-Silik. 55 (2011) 199-207.

[10] D.C. Greenspan, L.L. Hench, J. Biomed. Mater. Res. 10 (1976) 503-509.

[11] M. Vallet-Regi, I. Izquierdo-Barba, A.J. Salinas, J. Biomed. Mater. Res. 46 (1999) 560-565.

[12] M. Vallet-Regi, A.M. Romero, C.V. Ragel, R.Z. LeGeros, J. Biomed. Mater. Res. 44 (1999) 416-421.

[13] S. Falaize, S. Radin, P. Ducheyne, J. Am. Ceram. Soc. 82 (1999) 969-976.

[14] I. Izquierdo-Barba, A.J. Salinas, M. Vallet-Regi, J. Biomed. Mater. Res. 51 (2000) 191-199.

[15] A.H. De Aza, P. Velasquez, M.I. Alemany, P. Pena, P.N. De Aza, J. Am. Ceram. Soc. 90 (2007) 1200-1207.

[16] A.J. Salinas, M. Vallet-Regi, I. Izquierdo-Barba, J. Sol-Gel Sci. Technol. 21 (2001) $13-25$.

[17] A.L. Oliveira, P.B. Malafaya, S.A. Costa, R.A. Sousa, R.L. Reis, J. Mater. Sci.-Mater. Med. 18 (2007) 211-223.

[18] I.B. Leonor, A. Ito, K. Onuma, N. Kanzaki, R.L. Reis, Biomaterials 24 (2003) 579-585.

[19] N. Eliaz, W. Kopelovitch, L. Burstein, E. Kobayashi, T. Hanawa, J. Biomed. Mater. Res. Part A 89A (2009) 270-280.

[20] M. Cerruti, D. Greenspan, K. Powers, Biomaterials 26 (2005) 1665-1674.

[21] S.G. Caridade, E.G. Merino, N.M. Alves, J.F. Mano, Macromol. Biosci. 12 (2012) 1106-1113.

[22] S.G. Caridade, E.G. Merino, N.M. Alves, V.d.Z. Bermudez, A.R. Boccaccini, J.F. Mano, J. Mech. Behav. Biomed. Mater. 20 (2012) 173-183.

[23] J.F. Mano, R.L. Reis, A.M. Cunha, in: R.L. Reis, D. Cohn (Eds.), Dynamic Mechanical Analysis in Polymers for Medical Applications, Polymer Based Systems on Tissue Engineering, Replacement and RegenerationKluwer Academic Publishers, Netherlands, 2002, pp. 139-164.

[24] S. Ghosh, V. Gutierrez, C. Fernandez, M.A. Rodriguez-Perez, J.C. Viana, R.L. Reis, J.F. Mano, Acta Biomater. 4 (2008) 950-959.

[25] J.F. Mano, Macromol. Biosci. 8 (2008) 69-76.

[26] E.J. Lee, D.S. Shin, H.E. Kim, H.W. Kim, Y.H. Koh, J.H. Jang, Biomaterials 30 (2009) 743-750.

[27] J.F. Mano, G. Hungerford, J.L.G. Ribelles, Mater. Sci. Eng. C-Biomim. Supramol. Syst. 28 (2008) 1356-1365.

[28] J. Mota, N. Yu, S.G. Caridade, G.M. Luz, M.E. Gomes, R.L. Reis, J.A. Jansen, X.F. Walboomers, J.F. Mano, Acta Biomater. 8 (2012) 4173-4180.

[29] M. Swetha, K. Sahithi, A. Moorthi, N. Srinivasan, K. Ramasamy, N. Selvamurugan, Int. J. Biol. Macromol. 47 (2010) 1-4.

[30] I.B. Leonor, E.T. Baran, M. Kawashita, R.L. Reis, T. Kokubo, T. Nakamura, Acta Biomater. 4 (2008) 1349-1359.

[31] R.M.P. da Silva, J.F. Mano, R.L. Reis, Macromol. Chem. Phys. 209 (2008) 1463-1472.

[32] M. Terbojevich, A. Cosani, R.A.A. Muzzarelli, Carbohydr. Polym. 29 (1996) 63-68.

[33] T. Kokubo, H. Takadama, Biomaterials 27 (2006) 2907-2915. 